\title{
Pasteurização do leite-do-amapá in natura para controle do escurecimento enzimático
}

\author{
Pasteurization of the milk-of-amapá for control of enzymatic browning
}

\author{
Valeria Saldanha Bezerra' ${ }^{I}$ Rafaella de Andrade Mattietto ${ }^{\text {II }}$ Ednei Assunção Antunes Coelho ${ }^{\text {III }}$ \\ Fabio Ferreira de AguiarIII
}

\section{RESUMO}

O extrato do amapazeiro (Brosimum parinarioides Ducke), conhecido como leite-do-amapá, é utilizado pelas populações amazônicas como fonte alimentar e medicinal. A rápida alteração de cor do látex após extração representa a presença de enzimas como polifenoloxidase (PPO) e peroxidase $(P O D)$, escurecendo o produto in natura e desqualificando-o para comercialização. Desse modo, este trabalho objetivou a avaliação da atividade das enzimas PPO e POD em três amostras de leite-do-amapá resfriadas a $8^{\circ} \mathrm{C}$, coletadas em amapazeiros em Moju (PA), e onze amostras de leite-do-amapá após o processo de pasteurização em diversos binômios tempo/temperatura $e$ posteriormente resfriadas a $8^{\circ} \mathrm{C}$, visando à otimização da conservação do produto in natura. Após resfriamento $a 8^{\circ} \mathrm{C}$, as amostras de leite-do-amapá in natura apresentaram diferença significativa entre os valores de atividade da enzima POD e, posteriormente observou-se elevação dessa atividade durante os períodos de tempo analisados. Como também se observou atividade da enzima PPO nas mesmas amostras, constata-se que esse tipo de conservação não foi eficiente para as enzimas POD e PPO para leite-do-amapá. As amostras pasteurizadas de leitedo-amapá, e posteriormente resfriadas, apresentaram atividades das enzimas POD e PPO significativamente diferenciadas da respectiva amostra controle (sem pasteurização), concluindo que a pasteurização nos binômios estudados, aliada ao resfriamento, foi eficaz na diminuição da atividade das enzimas peroxidase e polifenoloxidase, alcançando-se a inativação destas, podendo ser um processo potencial para conservação desse produto.

Palavras-chave: leite-do-amapá, Brosimum, escurecimento, pasteurização, resfriamento.

\section{ABSTRACT}

The extract of amapazeiro (Brosimum parinarioides Ducke), known as milk-of-amapá, is used by Amazonian populations as food and medicinal sources. The rapid change in color of the latex after extraction indicates the presence of enzymes such as polyphenoloxidase (PPO) and peroxidase (POD), darkening the fresh product and disqualifying it for trading. Thus, this study aimed at evaluating the activity of enzymes PPO and POD from three milk-of-amapá samples collected in amapazeiros in Moju (PA) cooled to $8^{\circ} \mathrm{C}$ and eleven samples of milk-of-amapá after the pasteurization process in different binomials time / temperature and then cooled to $8^{\circ} \mathrm{C}$ in order to optimize the storage of the fresh product. After cooling to $8^{\circ} \mathrm{C}$, samples from the fresh milk-of-amapá showed significant difference between the values of PER enzyme activity $P O D$, and later there was an increase of activity during the periods analyzed. As it was also observed PPO enzyme activity in the same samples, it appears that this type of conservation was not effective for the POD and PPO enzymes from milk-of-amapá. The samples of pasteurized milk-of-Amapá, and then cooled, showed enzyme activities of $P P O$ and POD significantly different from respective control sample (without pasteurization), what leads to a conclusion that pasteurization in binomials studied, together with the cooling, was effective in reducing the activity of peroxidase and polyphenoloxidase enzymes, reaching to the inactivation of them, being a potencial process for conservation of this product.

Key words: milk-of-amapá, Brosimum, browning, pasteurization, cooling.

\section{INTRODUÇÃO}

O leite do amapá-doce é um exsudato de sabor adocicado, procedente de árvores de duas espécies do gênero Brosimum, sendo que os gêneros Parahancornia e Couma apresentam um látex comestível não elástico, conhecido como amapá amargosa (PLOWDEN, 2002). Pertencente à família Moraceae e tendo como habitat toda a Amazônia, o amapazeiro é comumente encontrado nas florestas de terra firme (LOUREIRO et al., 2000) nos estados

\footnotetext{
'Embrapa Amapá, 68903-419, Macapá, AP. Brasil. E-mail: valeria.bezerra@embrapa.br. Autor para correspondência.

IIEmbrapa Amazônia Oriental, Belém, PA,Brasil.

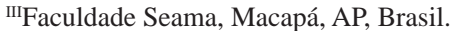


do Pará, Amapá, Amazonas, Mato Grosso e Goiás (PINTO et al., 2000), assim como na Guiana Francesa (DEFILIPPS et al., 2004).

No caule do amapazeiro, encontram-se canais laticíferos, produtores de látex, que é composto de uma mistura de moléculas compostas de açúcares, gomas, alcaloides, óleos essenciais e proteínas (PALHETA et al., 2009). A produção de látex pode variar, dependendo dos instrumentos utilizados na extração (GALUPPO et al., 2003), com potencial médio de 3,6 t/ano, sendo que, de uma árvore adulta, pode-se extrair, em média, 15 litros de leite vegetal (GONÇALVES, 2001).

O leite do amapá-doce é muito apreciado pelas comunidades rurais amazônidas, substituindo, muitas vezes, o leite bovino na alimentação humana (PALHETAet.al., 2009; GAI etal., 2009) ereconhecido pelo seu potencial tonificante e reconstituinte (GALUPPO et al., 2003), sendo utilizado em casos de desnutrição (FREITAS \& FERNANDES, 2006). O leite-do-amapá apresenta teores significativos em relação às proteínas (6\%), lipídeos (9\%) e fibras (2\%) e consequentemente bom valor energético (190kcal $\left.100 \mathrm{~g}^{-1}\right)$, assim como se destaca quantos aos teores de cálcio (200,63mg kg-1), fósforo (149,53 $\left.\mathrm{mg} \mathrm{kg}^{-1}\right)$ e potássio (1.862,06mg kg-1) em relação aos demais minerais (MATTIETTO et al., 2009), com valores bastante próximos ao que é recomendado na alimentação diária (SATO, 2004). Em estudos recentes, o látex do amapazeiro, por apresentar atividade antioxidante, também pode ser considerado potencialmente um alimento nutracêutico com aplicação em diversos processos industriais (PALHETA et al., 2009).

$\mathrm{Na}$ medicina popular regional, é muitas vezes utilizado como medicamento, devendo ser administrado em pequenas doses (PINTO et al., 2000), em tratamentos para inflamação do útero (LOUREIRO \& MACEDO, 1999), doenças respiratórias (SANTOS et al., 2012), gastrite, anemia e problemas musculares (GALUPPO et al., 2003; RODRIGUES, 2006).

Após a extração do látex, observa-se uma rápida mudança de cor, com um escurecimento característico do branco para rosado, quando o leite-do-amapá é exposto ao ar livre, devido à presença de enzimas oxidativas como a polifenoloxidase (MATTIETTO et al., 2009). A enzima polifenoloxidase tem sido objeto de contínua atenção, pois a reação de escurecimento em frutas, vegetais e bebidas é um dos principais problemas na indústria de alimentos (ARAÚJO, 1995). As polifenoloxidases (EC 1.14.18.1) pertencem ao grupo das oxirredutases, que oxidam fenóis a O-quinonas na presença de oxigênio molecular (MATHEIS,
1983). Peroxidases (EC 1.11.1.7) são um grupo de oxirredutases que catalisam a redução de peróxidos, tais como peróxido de hidrogênio e a oxidação de uma variedade de compostos orgânicos e inorgânicos (HAMID \& REHMAN, 2009). Na pós-colheita, as peroxidases também são responsáveis por perda na cor, flavor, textura, bem como do valor nutricional (ARAÚJO,1995) e é considerada uma das enzimas mais temorresistentes, sendo utilizada para testar a eficiência do processamento térmico de frutas e vegetais antes de seu congelamento e armazenamento (FENNEMA, 1993).

Desse modo, este trabalho teve por objetivo analisar o leite-do-amapá in natura em relação às atividades das enzimas polifenoloxidase e peroxidase e o processamento térmico, visando à otimização do processo de conservação do produto.

\section{MATERIAL E MÉTODOS}

O leite-do-amapá foi coletado por duas vezes de três árvores nativas de amapá-doce (Brosimum parinarioides Ducke) no Campus Experimental da Embrapa Amazônia Oriental, localizado no município de Moju (PA), sendo reconhecidas cientificamente por um identificador botânico. A extração do látex do tronco foi realizada através de cortes transversais, pelo período da manhã, e, imediatamente após os cortes, amostras do látex foram recolhidas em frascos de vidro, previamente esterilizados para evitar alterações em sua composição, permanecendo resfriadas a $8^{\circ} \mathrm{C}$. As amostras foram analisadas quanto ao comportamento das enzimas peroxidase e polifenoloxidase no Laboratório de Alimentos da Embrapa Amapá. Na primeira coleta, o material foi simplesmente resfriado a $8^{\circ} \mathrm{C}$ e, na tentativa de conservar o leite do amapádoce, um tratamento térmico foi otimizado para a segunda coleta, no qual o binômio temperatura $\left(\mathrm{X}_{1}\right)$ e tempo $\left(\mathrm{X}_{2}\right)$ seguiu um delineamento fatorial completo (BARROS NETO et al., 1996), tendo como respostas as avaliações enzimáticas: peroxidase e polifenoloxidase. A tabela 1 mostra o planejamento experimental adotado nos testes de conservação do produto. Todas as respostas do planejamento experimental proposto foram analisadas com o auxílio do software Statistica ${ }^{\circledR}$ versão 5.0.

O leite do amapá foi acondicionado em tubos de vidro com rosca, previamente esterilizados em autoclave a $121^{\circ} \mathrm{C}$ por 15 minutos, com o intuito de inibir qualquer contaminação oriunda do próprio tubo. O processo de pasteurização de cada ensaio foi realizado em banho-maria marca TECNAL TE0532, com controle de temperatura durante todo o processo 
Tabela 1 - Temperatura e tempo aplicados variando de acordo com os níveis codificados.

\begin{tabular}{lllllll}
\hline & \multicolumn{5}{c}{ Níveis codificados e reais das } \\
Variáveis Independentes & -------- variáveis independentes------- \\
\hline & $-1,41$ & -1 & 0 & +1 & $+1,41$ \\
$\mathrm{X}_{1}$ (Temperatura em $\left.{ }^{\circ} \mathrm{C}\right)$ & 83 & 85 & 90 & 95 & 97 \\
$\mathrm{X} 2$ (Tempo em min) & 0,88 & 1,5 & 3 & 4,5 & 5,12 \\
\hline
\end{tabular}

(medição de temperatura em um tubo aberto, atuando como controle). Após pasteurização e resfriamento rápido em água corrente, a estocagem das amostras pasteurizadas foi realizada sob refrigeração.

As análises de atividades enzimáticas da polifenoloxidase e da peroxidase em leite-doamapá foram adaptadas até a obtenção de um extrato enzimático que alcançasse leitura espectrofotométrica. A atividade enzimática da polifenoloxidase foi determinada de acordo com técnica descrita por PONTING \& JOSLYN (1948) e algumas modificações, pois, além de atuar nos principais substratos como compostos aromáticos, também podem atuar sobre compostos não-aromáticos, como o ácido ascórbico (CAMPOS \& SILVEIRA, 2003). O extrato enzimático foi obtido pela homogeneização de $5 \mathrm{~g}$ de amostra para $25 \mathrm{~mL}$ tampão fosfato $0,05 \mathrm{M}$, $\mathrm{pH} 7,0$. Após a filtragem em papel de filtro Whatman $\mathrm{n}^{\mathrm{o}} 1$, tomou-se $0,1 \mathrm{~mL}$ do extrato enzimático, $3,6 \mathrm{~mL}$ tampão fosfato $0,1 \mathrm{M}$ (pH 6,0) e incubou-se com $0,1 \mathrm{~mL}$ catecol $10 \mathrm{mM}$ por 30 minutos a $30^{\circ} \mathrm{C}$. A reação foi interrompida pela adição de 1,6mL ácido perclórico $2 N$. Procedeu-se à leitura dos valores de absorbância em espectrofotômetro no comprimento de onda de $395 \mathrm{~nm}$, sendo a atividade da polifenoloxidase expressa em $\mathrm{U} \mathrm{g}^{-1}$ minuto $^{-1}$. A atividade enzimática da peroxidase foi determinada de acordo com a técnica descrita por FEHRMAN \& DIMOND (1967), com modificações para mandioca (BEZERRA, 2000), para a qual se utilizou o mesmo extrato do doseamento de atividade da polifenoloxidase. Para o doseamento, utilizaram-se $0,1 \mathrm{~mL}$ de extrato enzimático; $5,0 \mathrm{~mL}$ tampão fosfato-citrato $0,2 \mathrm{M}\left(\mathrm{pH} \mathrm{5,0);0,5mL} \mathrm{H}_{2} \mathrm{O}_{2}\right.$ $3 \%$, incubados com $0,5 \mathrm{~mL}$ guaiacol, a $30^{\circ} \mathrm{C}$ por 5 minutos. Interrompeu-se a reação pela adição de 1,0mL bissulfito de sódio 30\% e procedeu-se à leitura em espectrofotômetro no comprimento de onda de $470 \mathrm{~nm}$, sendo a atividade da peroxidase expressa em $\mathrm{U} \mathrm{g}^{-1}$ minuto $^{-1}$.

Da primeira coleta de látex, o material não pasteurizado foi analisado quanto à atividade da enzima peroxidase a 470nm, em dois períodos, sendo o primeiro às $8 \mathrm{~h}$ e o segundo às $11 \mathrm{~h} 30 \mathrm{~min}$ da manhã, utilizandose o espectrofotômetro Analyser Mod. 800 Digital, para avaliação do comportamento da enzima durante o período. A leitura da atividade da polifenoloxidase a 395nm foi feita às $16 \mathrm{~h}$ no espectrofotômetro marca Varian Cary 50 Conc. UV-Visible.

Da segunda coleta de látex, as 12 amostras foram analisadas no espectrofotômetro marca Varian Cary 50 Conc. UV-Visible, tanto para atividade de peroxidase, quanto para fenoloxidase. Todos os dados foram analisados no delineamento blocos ao acaso balanceados pelo programa SAS 9.2 TS Level 2MO (STATISTICAL...2010).

\section{RESULTADOS E DISCUSSÃO}

Na primeira coleta, em que os materiais coletados apenas foram resfriados a $8^{\circ} \mathrm{C}$, a atividade da enzima peroxidase da amostra $2\left(0,4142 \mathrm{U} \mathrm{g}^{-1}\right.$ minuto $\left.^{-1}\right)$ diferenciou-se significativamente das amostras $1\left(0,2552 \mathrm{U} \mathrm{g}^{-1}\right.$ minuto $\left.^{-1}\right)$ e $3\left(0,2486 \mathrm{U} \mathrm{g}^{-1}\right.$ minuto $\left.^{-1}\right)$ em avaliação realizada às $8 \mathrm{~h}$ da manhã. $\mathrm{O}$ mesmo desempenho atividade da POD foi observado na amostra $2\left(0,7492 \mathrm{U} \mathrm{g}^{-1}\right.$ minuto $\left.^{-1}\right)$, ao ser avaliada às $11 \mathrm{~h} 29 \mathrm{~min}$, em relação às amostras $1\left(0,4964 \mathrm{U} \mathrm{g}^{-1}\right.$ minuto $\left.^{-1}\right)$ e $3\left(0,4632 \mathrm{U} \mathrm{g}^{-1}\right.$ minuto $\left.^{-1}\right)$ (Tabela 2).

$\mathrm{Na}$ análise realizada às $8 \mathrm{~h}$ da manhã, a atividade da enzima peroxidase da amostra 2 representou uma elevação de 62,3\% e 66,6\% na atividade da enzima em relação às amostras 1 e 3 , respectivamente (Figura 1). Já na análise realizada às

Tabela 2 - Atividade da enzima peroxidase e polifenoloxidase em amostras de leite-do-amapá sob refrigeração a $8^{\circ} \mathrm{C}$.

\begin{tabular}{|c|c|c|c|}
\hline \multirow[t]{2}{*}{ Amostra de Leite-do-amapá } & \multicolumn{2}{|c|}{ 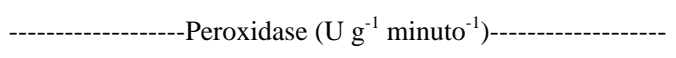 } & \multirow{2}{*}{$\frac{\text { Polifenoloxidase }\left(\mathrm{U} \mathrm{g}^{-1} \text { minuto }^{-1}\right)}{16 \mathrm{~h}}$} \\
\hline & $8 \mathrm{~h}$ & $11: 29 \mathrm{~h}$ & \\
\hline Amostra 1 & $0,2552 \mathrm{~b}^{*}$ & $0,4964 \mathrm{~b}$ & 1,4317 a \\
\hline Amostra 2 & 0,4142 a & 0,7492 a & 1,3574 a \\
\hline Amostra 3 & $0,2486 \mathrm{~b}$ & $0,4632 b$ & $1,1259 \mathrm{~b}$ \\
\hline Média & 0,3063 & 0,5696 & 1,3050 \\
\hline $\mathrm{CV}$ & 7,476 & 6,929 & 3,447 \\
\hline
\end{tabular}

*Médias seguidas por letras distintas diferem entre si ao nível de 5\% na mesma coluna. 


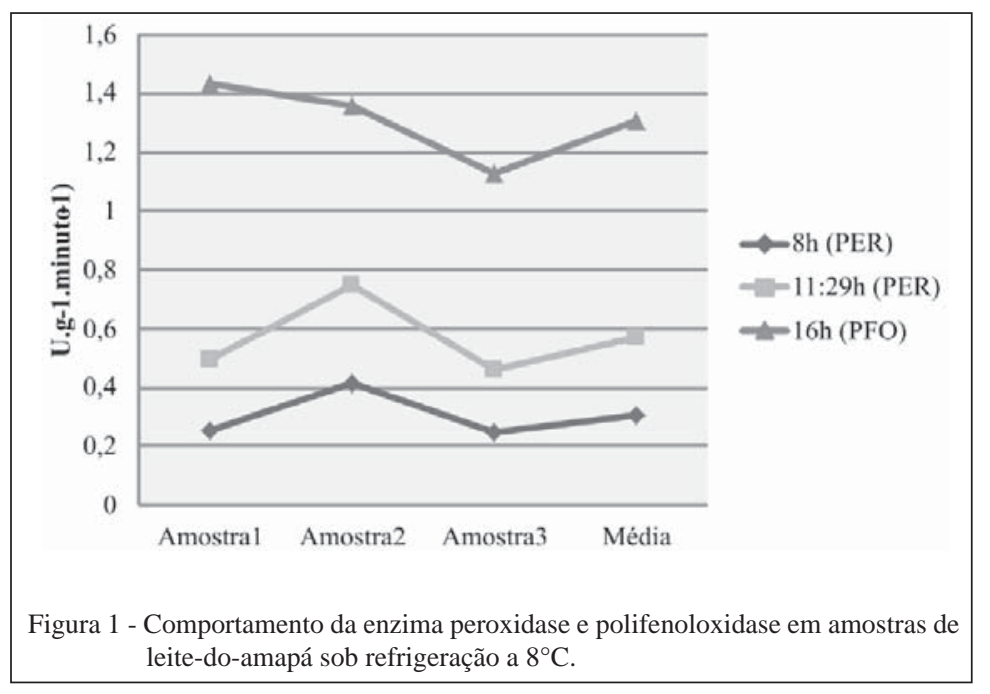

11h29min da manhã, observaram-se menores níveis relativos do que a análise anterior, quanto à elevação da atividade da enzima peroxidase na amostra 2, quando comparada à amostra 1 (50,93\%) e amostra 3 (61,74\%). No período de tempo compreendido entre as duas análises, observou-se que houve uma elevação na média da atividade da peroxidase de 85,96\% (Figura 1), mesmo estando as amostras conservadas sob refrigeração. Essa diferenciação na atividade enzimática, observada sob condições similares de coleta, pode ser explicada pela própria diversidade genética dos materiais coletados, pela idade ou mesmo pelas condições edafoclimáticas diferenciadas em que essas matrizes se encontram.

Quanto à atividade da enzima polifenoloxidase em amostras sob refrigeração a $8^{\circ} \mathrm{C}$, a amostra $3\left(1,1259 \mathrm{U} \mathrm{g}^{-1}\right.$ minuto $\left.^{-1}\right)$ diferenciouse significativamente da amostra $1\left(1,4317 \mathrm{U} \mathrm{g}^{-1}\right.$ minuto $\left.^{-1}\right)$ e da amostra $2\left(1,3574 \mathrm{U} \mathrm{g}^{-1}\right.$ minuto $\left.^{-1}\right)$ (Tabela 2). Ao analisarmos a tabela 3, observamos que a amostra controle, ou seja, a amostra in natura sem pasteurização foi a única que se diferenciou significativamente das demais amostras, tanto em relação à atividade da enzima peroxidase $(0,6817 \mathrm{U}$ $\mathrm{g}^{-1}$ minuto $\left.^{-1}\right)$, quanto da polifenoloxidase $\left(0,8029 \mathrm{U} \mathrm{g}^{-1}\right.$ minuto $\left.^{-1}\right)$.

Ao compararmos a média da atividade de peroxidase das amostras pasteurizadas $\left(0,0063 \mathrm{U} \mathrm{g}^{-1}\right.$ minuto $^{-1}$ ) com a média da amostra sem pasteurização $\left(0,6817 \mathrm{Ug} \mathrm{g}^{-1}\right.$ minuto $\left.^{-1}\right)$, observamos queapasteurização do leite-do-amapá levou à redução na atividade da enzima peroxidase em 99,08\% (Figura 2). Em

Tabela 3 - Atividade da enzima peroxidase e polifenoloxidase em amostras de leite-do-amapá após pasteurização.

\begin{tabular}{lcc}
\hline Níveis de pasteurização (temperatura/tempo) & Peroxidase $\left(\mathrm{U} \mathrm{g}^{-1}\right.$ minuto $\left.^{-1}\right)$ & Polifenoloxidase $^{\left(\mathrm{U} \mathrm{g}^{-1} \text { minuto }^{-1}\right)}$ \\
\hline Sem pasteurização & $0,6817 \mathrm{a}$ & $0,8028 \mathrm{a}$ \\
$85^{\circ} \mathrm{C} / 1,5 \mathrm{~min}$ & $0,0173 \mathrm{~b}$ & $0,0332 \mathrm{~b}$ \\
$95^{\circ} \mathrm{C} / 1,5 \mathrm{~min}$ & $0,0050 \mathrm{~b}$ & $0,0171 \mathrm{~b}$ \\
$85^{\circ} \mathrm{C} / 4,5 \mathrm{~min}$ & $0,0075 \mathrm{~b}$ & $0,0180 \mathrm{~b}$ \\
$95^{\circ} \mathrm{C} / 4,5 \mathrm{~min}$ & $0,0068 \mathrm{~b}$ & $0,0173 \mathrm{~b}$ \\
$90^{\circ} \mathrm{C} / 3 \min$ & $0,0028 \mathrm{~b}$ & $0,0144 \mathrm{~b}$ \\
$90^{\circ} \mathrm{C} / 3 \min$ & $0,0040 \mathrm{~b}$ & $0,0170 \mathrm{~b}$ \\
$90^{\circ} \mathrm{C} / 3 \min$ & $0,0040 \mathrm{~b}$ & $0,0185 \mathrm{~b}$ \\
$83^{\circ} \mathrm{C} / 3 \min$ & $0,0065 \mathrm{~b}$ & $0,0238 \mathrm{~b}$ \\
$97^{\circ} \mathrm{C} / 3 \min$ & $0,0039 \mathrm{~b}$ & $0,0120 \mathrm{~b}$ \\
$90^{\circ} \mathrm{C} / 0,88 \min$ & $0,0071 \mathrm{~b}$ & $0,0195 \mathrm{~b}$ \\
$90^{\circ} \mathrm{C} / 5,12 \min$ & $0,0045 \mathrm{~b}$ & $0,0165 \mathrm{~b}$ \\
Média geral & 0,0626 & 0,0848 \\
Média amostras pasteurizadas & 0,0063 & 0,0188 \\
\hline
\end{tabular}

Médias seguidas por letras distintas diferem entre si em nível de 5\%. 


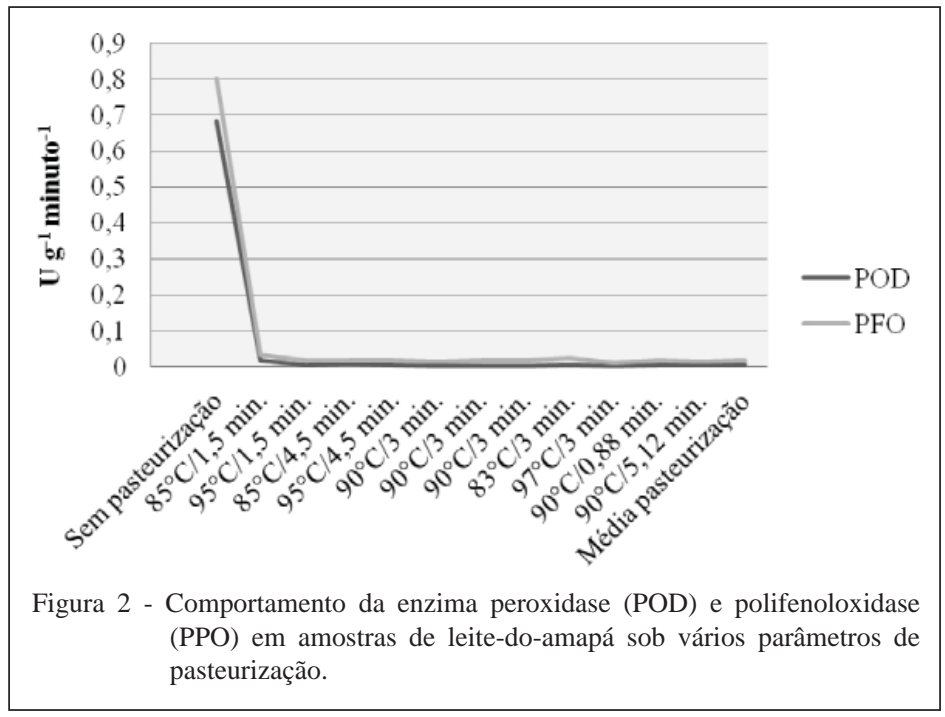

relação à enzima polifenoloxidase, observamos que a pasteurização acarretou numa redução de 97,65\% da atividade da enzima na média das amostras de leite-do-amapá pasteurizadas $\left(0,0188 \mathrm{U} \mathrm{g}^{-1}\right.$ minuto $\left.^{-1}\right)$, quando comparadas à atividade da enzima na amostra controle $\left(0,8028 \mathrm{U} \mathrm{g}^{-1}\right.$ minuto $\left.^{-1}\right)$ (Figura 2$)$.

As atividades das enzimas peroxidase e polifenoloxidase somente não foram inativadas quando a pasteurização foi realizada a $85^{\circ} \mathrm{C}$ durante 1,5min. A inativação de ambas as enzimas foi alcançada pela exposição do extrato enzimático a um tempo de exposição maior ao calor $\left(85^{\circ} \mathrm{C}\right.$ por $4,5 \mathrm{~min})$ e a uma temperatura menor $\left(83^{\circ} \mathrm{C}\right)$ e tempo de exposição maior (3min) (Tabela 3).

\section{CONCLUSÃO}

A conservação sob refrigeração a $8^{\circ} \mathrm{C}$ não foi efetiva para controle da reações enzimáticas (peroxidase e polifenoloxidase) no leite-do-amapá. O tratamento térmico por pasteurização em leite-doamapá, seguido de resfriamento, pode ser eficiente na diminuição das atividades das enzimas peroxidase e polifenoloxidase, em qualquer nível de temperatura e tempo estudados.

A diminuição efetiva da atividade das enzimas peroxidase e polifenoloxidase em leitedo-amapá foi alcançada durante a pasteurização na menor temperatura estudada de $83^{\circ} \mathrm{C}$ por $3 \mathrm{~min}$, ou no menor tempo de exposição de $1,5 \mathrm{~min}$ à temperatura de $95^{\circ} \mathrm{C}$. O tratamento térmico por pasteurização, nas condições de tempo-temperatura estudadas, alcançou a inativação das enzimas peroxidase e polifenoloxidase em amostras de leite-do-amapá.

\section{AGRADECIMENTO}

Os autores agradecem ao Conselho Nacional de Desenvolvimento Científico e Tecnológico (CNPq), pelo apoio financeiro à execução deste projeto.

\section{REFERÊNCIAS}

ARAÚJO, J.M.A. Química de alimentos: teoria e prática. Viçosa: UFV, 1995. 335p.

BARROS NETO, B. et al. Planejamento e otimização de experimentos. Campinas: UNICAMP, 1996. 299p.

BEZERRA, V.S. Alterações na composição química e cocção de raízes de mandioca (Manihot esculenta Crantz) minimamente processadas. 2000. 92f. Dissertação (Mestrado em Ciência dos Alimentos) - Universidade Federal de Lavras, MG.

CAMPOS, A.D.; SILVEIRA, E.M. da L. Metodologia para determinação da peroxidase e da polifenol oxidase em plantas. Pelotas: Embrapa Clima Temperado, 2003. 3p. (Embrapa Clima Temperado. Comunicado técnico, 87).

DEFILIPPS, R.A. et al. Medicinal plants of the Guianas (Guyana, Surinam, French Guiana). Biological diversity of the guiana shield program, Smithsonian Institution, 2004. (web publication only). p.190. Disponível em: <http://botany.si.edu/ bdg/medicinal/MedPlantsGui3.pdf. Acesso: em 02 dez. 2010.

FENNEMA, O.R. Química de los alimentos. Zaragoza: Acribia, 1993. 1095p.

FEHRMAN, H.; DIMOND, A.E. Peroxidase activity and phytophthora resistance in different organs of the potato plant. Phytopathology, v.57, p. 69-72, 1967.

FREITAS, J.C. de; FERNANDES, M.E.B. Uso de plantas medicinais pela comunidade de Enfarrusca, município de Bragança, Pará. Boletim do Museu Paraense Emílio Goeldi, Série Ciências Naturais, Belém, v.1, n.3, p.11-26, 2006. 
GAI, J.E.M. et al. Composição inorgânica de leite de amapá (Brosimum parinarioides, Brosimum potabile e Brosimum utile ovatifolium). In: REUNIÃO ANUAL DA SOCIEDADE BRASILEIRA DE QUÍMICOS, 32., 2009, Fortaleza, CE. Resumos... Fortaleza: SBQ, 2009. n.p. Acessado em 17 ago. 2011. Online. Disponível em: http://sec.sbq.org.br/cdrom/32ra/resumos/ T0443-1.pdf.

GALUPPO, S.C. et al. Utilização do amapá-doce (Brosimum parinarioides Ducke), na comunidade de Piquiatuba, Belterra-PA. In: CONGRESSO NACIONAL DE BOTÂNICA, 54.; REUNIÃO AMAZÔNICA DE BOTÂNICA, 3., 2003, Belém, PA. Resumos. Belém, PA: Sociedade Botânica do Brasil / UFRA: Museu Paraense Emílio Goeldi: Embrapa Amazônia Oriental, 2003. 1 CD-ROM.

GONÇALVES, V.A. Levantamento de mercado de produtos florestais não-madeireiros. Santarém: ProManejo/IBAMA, 2001. 65p.

HAMID, M.; REHMAN, K. Potencial applications of peroxidases. Food Chemistry, v.115, n.4, p.1177-1186, 2009.

LOUREIRO, A.A. de et al. Essências madeireiras da Amazônia. Manaus: MCT/INPA-CPPF, 2000. V.4, 191p.

LOUREIRO, R.N.O.; MACEDO, M. Uso de vegetais na medicina caseira da comunidade rural de Baxiu, pantanal de Cáceres, Mato Grosso. In: CONGRESSO NACIONAL DE BOTÂNICA, 50., 1999, Blumenau, SC. Programa e resumos... Blumenau: Sociedade Botânica do Brasil, 1999. p.287.

MATHEIS, G. Enzymatic browning of foods. Z Lebensm Unters Forsch, v.176, p.454-462, 1983.

MATTIETTO, R.A. et al. Otimização do processo de conservação do leite de amapá-doce (Brosimum parinarioides Ducke). In: CONFERÊNCIA DO SUBPROGRAMA DE CIÊNCIA E
TECNOLOGIA - SPC\&T FASE II/PPG7, 2008, Belém, PA. Anais... Brasília, DF: CNPq, 2009. p.352-354.

PALHETA, R.A. et al. Atividade da protease, qualidade microbiológica e atividade antioxidante do látex de Brosimum parinarioides. In: REUNIÃO ANUAL DA SBPC, 61., 2009, Manaus, AM. Resumos e comunicações livres... Manaus: SBPC/UFAM, 2009. n.p. Acessado em 17 ago. 2011. Online. Disponível em: <http://www.sbpcnet.org.br/ livro/61ra/resumos/resumos/5888.htm>.

SANTOS, J. de F.L. et al. Observations on the therapeutic practices of riverine communities of the Unini River, AM, Brazil. Journal of Ethnopharmacology, v.142, n.2, p.503-515, 2012.

PINTO, J.E.B.P. et al. Compêndio de plantas medicinais. Lavras, MG: UFLA, 2000. 205p. il. (UFLA. Curso de Plantas medicinais: manejo, uso e manipulação).

PLOWDEN, C. Amapá (Parahancornia spp. and Brosimm spp.). In: SHANLEY, P. et al. (Ed.). Tapping the green market: certification and management of non-timber forest products. London: Easthscan, 2002. p.123-125. (People and Plants Conservations Series).

PONTING, J.D.; JOSLYN, M.A. Ascorbic acid and browning in apple tissue extracts. Archives of Biochemistry, v.19, p.47-63, 1948.

RODRIGUES, E. Plants and animals utilized as medicines in the Jaú National park (JNP), Brazilian Amazon. Phytotherapy Research, v.20, p.378-391, 2006.

SATO, R. Pesquisa comprova o valor medicinal e nutricional de espécies amazônicas. 2004. Disponível em: <http:// www.embrapa.br/imprensa/noticias/2004/junho/bn.2004-1125.1383596589/>. Acesso em: 17 ago. 2011.

SAS. Statistical Analysis System. Cary, 2010. Disponível em: $<$ http://www.sas.com/offices/latinamerica/brazil/govedu/professores. html>. Acesso em: 20 maio, 2010. 